http://jmscr.igmpublication.org/home/ ISSN (e)-2347-176x ISSN (p) 2455-0450

crossref DOI: https://dx.doi.org/10.18535/jmscr/v8i12.47

\title{
Effect of Kangaroo Mother Care on Growth Parameters of AGA \& SGA Preterm Low Birth Weight Neonates
}

\author{
Authors \\ Dr Priyanka Mistry ${ }^{1}$, Dr Arif Vohra ${ }^{2}$, Dr Jolly Vaishnav ${ }^{3}$, Dr Aditya Kushwaha ${ }^{4}$ \\ ${ }^{1}$ Resident Doctor, ${ }^{2}$ Assistant Professor, ${ }^{3}$ Head of Department, ${ }^{4}$ Resident Doctor \\ BJMC Paediatrics
}

\begin{abstract}
Objectives: Low birth weight $(B W<2500 \mathrm{~g})$, which is often associated with preterm birth, is a common problem in India. Both are recognized risk factors for neonatal mortality. Kangaroo mother care (KMC) is a non-conventional, low-cost method for newborn care based upon intimate skin-to-skin contact between mother and baby. Our objective was to assess the effect of provision of adequate KMC to the SGA and AGA neonates and perform a comparative study of its effectiveness in both groups.

Materials and Methods: In a prospective hospital based study, during the period of 6months, from 1st January 2019 to 31st June 2019, 4186 consecutively delivered live newborns were studied for the incidence of low birth weight neonates and prematurity and to comparatively evaluate the potential of Kangaroo Mather Care (KMC) on growth parameters for low birth weight (LBW) neonates, which were divided into two study groups of AGA (Appropriate for Gestational Age) and SGA (Small for Gestational Age).

Results: Data from 282 mother-baby pairs were analysed. Improvements occurred in all 4 physiological parameters during the KMC sessions. Mean temperature rose by about $0.4^{\circ} \mathrm{C}, \mathrm{RR}$ by $3 / \mathrm{minute}$, HR by 5 bpm, and $\mathrm{SpO}_{2}$ by $5 \%$ following KMC sessions. Although modest, these changes were statistically significant. Individual abnormalities (e.g. hypothermia, bradycardia, tachycardia, low $\mathrm{SpO}_{2}$ ) were often corrected during the KMC sessions.

Conclusions: Babies receiving KMC showed statistically significant improvement in vital physiological parameters. Thus, without using special equipment, the KMC strategy can offer improved care to LBW babies. These findings support wider implementation of this strategy.

Keywords: India, kangaroo mother care, low birth weight, newborn, physiological parameter, preterm.
\end{abstract}

\section{Introduction}

The incidence of low birth weight neonates in India varies between $25-30 \%$, making it the country with highest number of LBW births. ${ }^{(1)}$ These neonates are at a greater risk of developing of hypothermia, hypoglycaemia, shock, feeding difficulties, respiratory distress and nosocomial infections $^{(2)}$; hence more emphasis has to be put on monitoring and early intervention in betterment of these neonates. Also, on further follow up, SGA neonates are at a greater risk of delayed development and growth retardation as compared to AGA neonates, thus making it even more important for the health system to stress on care of SGA neonates during early days of their lives. Therefore, the care of such infants becomes a 
burden for health and social systems everywhere. Various low cost as well as modern treatment protocols are directed towards the care of such LBW neonates. Kangaroo Mother Care (KMC) is one of the low cost measures but most effective way to nurturing such high risk neonates ${ }^{(3)(4)}$.

Even Cochrane review have proved various benefits of KMC in LBW neonates ${ }^{(5)}$ like prevention of hypoglycaemia, hypothermia, decrease hospital duration, prevention of apnoea, decrease nosocomial infection, decrease oxygen requirements, early discharge and exclusively breastfeeding. Various studies have been conducted proving the role of KMC in betterment of the outcome of newborn care; ${ }^{(6)(7)(8)(9)}$ but there is hardly any study describing the difference in its role and difference in outcome in case of AGA and SGA preterm neonates specially growth parameters. This study was thus conducted with a view to analyse if there are any differences in preterm growth parameters with practice of KMC in Small for gestational age (SGA) neonates with respect to appropriate for gestational age (AGA) preterm neonates.

\section{Material and Methods}

A prospective cohort study was carried out at the NICU of Civil Hospital, Ahmadabad for a period of 6months; from $1^{\text {st }}$ January 2019 to $31^{\text {st }}$ June 2019. Preterm neonates who were intramural delivered and admitted in NICU, hemodynamically stable, and whose birth weight was less than $2500 \mathrm{~g}$ were enrolled in the study after obtaining a well-informed written consent.

Preterm neonates with birth weight $>2500 \mathrm{~g}$, fullterm neonates, hemodynamically Unstable/ Critically ill Preterm neonates, unwell Mother and/or unwilling mother \& family for providing KMC, malformed preterm babies and babies brought from postnatal ward were excluded from the study.

All the neonates were initially stabilized and then enrolled in the study. All enrolled neonates were divided into two groups according to their birth weight \& gestation age. Group A: Low birth weight preterm neonates with appropriate for gestational age (LBW Preterm AGA), and Group $B$ : Low birth weight preterm neonates with small for gestational age (LBW Preterm SGA). After enrolment, KMC was provided in both group, in a special KMC chair or Fowlers bed after counselling of the mother and the family. KMC instructions were given by the same individual, as according to the practical guidelines provided by the $\mathrm{WHO},{ }^{(1)}$ in both the groups to avoid bias. Special KMC chairs and KMC gowns were provided to the $\mathrm{KMC}$ provider. Basic demographic data, the age of the neonate at enrolment, frequency and duration of $\mathrm{KMC}$ and other details were recorded in pre structured proforma.

The infants were weighed naked on a Conweigh Electronic weighing scale, having an error of \pm 5 grams, immediately after birth, at enrolment at study and then once daily till discharge and it was recorded in proforma in both the groups. The length was measured at birth, at the time of enrolment, then weekly till discharge using an infantometer in both the groups. The Head Circumference (HC) was measured at 24 hours of birth, upon enrolment in the study, followed by once a week, at discharge using a non-elastic measure tape in both the groups. All data were recorded in proforma and statistical Analysis of data was done using the SAS University Edition software. Neonates fulfilling the discharging criteria were discharged but with counselling to provide KMC to the baby at home. Statistical Analysis was done using the SAS University Edition software.

\section{Results}

There were 4186 intramural deliveries during study period out of which, 1760 (42\%) were Low Birth Weight Neonates and 1219 (29\%) were preterm neonates. Out of 1219 preterm neonates, $282(23 \%)$ neonates were enrolled in the study.

In the study group, $47 \%$ were male neonates, mean birth-weight was $1436 \pm 267$ grams, gestational age was $32.18 \pm 2.43$ weeks neonates. 
Mean age of enrolment was 5.4 days. Mean duration of hospital stay was 12.1 days and the neonates received an average of $9 \pm 5$ days of
KMC. Mean hours of KMC received during this period was $10.7 \pm 6.2$ hours/day.

\begin{tabular}{|c|c|c|c|c|c|}
\hline \multicolumn{2}{|c|}{ Birth weight in grams } & \multicolumn{2}{|c|}{ Distribution of preterm neonates } & \multicolumn{2}{|c|}{ Gestational age } \\
\hline$<1000$ & 7 & \multirow[t]{2}{*}{ Preterm AGA } & \multirow[t]{2}{*}{236} & $<28$ weeks & 3 \\
\hline 1000-1499 & 113 & & & 28- 30 weeks & 6 \\
\hline $1500-1999$ & 137 & \multirow[t]{2}{*}{ Preterm SGA } & \multirow[t]{2}{*}{46} & 30- 32 weeks & 60 \\
\hline 2000- 2499 & 25 & & & 32- 34 weeks & 152 \\
\hline \multirow{3}{*}{$\begin{array}{l}\text { Mean: } \\
1436 \pm 267 \text { grams }\end{array}$} & \multirow[t]{3}{*}{$\mathrm{N}=282$} & & \multirow[t]{3}{*}{$\mathrm{N}=282$} & 34- 36 weeks & 48 \\
\hline & & & & 36- 37 weeks & 13 \\
\hline & & & & $\begin{array}{c}\text { Mean }= \\
32.18 \pm 2.43 \text { weeks }\end{array}$ & $\mathrm{N}=282$ \\
\hline
\end{tabular}

Effects of KMC on weight, head circumference and length with respect to duration of KMC in the both groups are summarized below.

Effect on growth of neonates according to LBW group:

\begin{tabular}{|l|c|c|c|}
\hline Group & $\begin{array}{c}\text { Group A } \\
\text { Preterm AGA }\end{array}$ & $\begin{array}{c}\text { Group B } \\
\text { Preterm SGA }\end{array}$ & p-value \\
\hline No of Neonates (n=282) & 236 & 46 & \\
\hline Mean hours of KMC (hours/day) & 10.6 & 11.3 & 0.98 \\
\hline Mean weight gain (gm/day) & $18.63 \pm 3.62$ & $21.41 \pm 5.26$ & 0.029 \\
\hline Mean Increment in Head Circumference (cm/week) & $0.605 \pm 0.044$ & $0.638 \pm 0.041$ & 0.024 \\
\hline Mean increment in length (cm/week) & $0.912 \pm 0.073$ & $0.926 \pm 0.27$ & 0.032 \\
\hline
\end{tabular}

\section{Discussion}

During the study period of 6 months, 4186 neonates were delivered at the institute, out of which, 1760 (42\%) were Low Birth Weight Neonates and 1219 (29\%) were preterm neonates. $6.73 \%$ of total inborn neonates i.e. 282 neonates were enrolled in the study, which consists of $23 \%$ of total preterm neonates delivered at the institute. Among all the enrolled neonates, 3 neonates (1\% of total enrolled preterm neonates) were extreme preterm ( $<28$ weeks) and 7 neonates $(2.4 \%$ of the total enrolled preterm neonates) were ELBW (birth weight $<1000$ grams).

Mean age of enrolment of neonates was 5.4 days as most of the infants were enrolled after they were hemodynamically stable ${ }^{(10)(11)} .48 \%$ of the enrolled neonates have received either invasive or non-invasive respiratory support and there were enrolled after they have been weaned from respiratory support. $35 \%$ neonates were enrolled within 72 hours of birth while 4 were enrolled after a period of 2 weeks of life as they were required ventilatory support. All neonates enrolled received KMC by their mothers, except for 6 cases where mothers were unable to provide KMC due to medical reasons and was provided by a close female relative and in 2 cases, KMC was provided by the father as he was the only the only guardian available. In 46 cases, Grandmothers and in 24 cases, aunts played a supportive role to the mother and thereby helping provide prolonged duration KMC.

Mean weight gain in LBW preterm SGA Neonate was $21.41 \pm 5.26$ grams/day as compared to LBW preterm AGA neonates with mean weight gain of $18.63 \pm 3.62$ grams/day, with equal duration of $\mathrm{KMC}$, and this difference was statistically significant $(\mathrm{p}=0.029)$. There was statically significant difference in mean increment of Head circumference noted in SGA neonates $(0.635 \pm 0.051 \mathrm{~cm} /$ week) as compare to AGA group $(0.605 \pm 0.044 \mathrm{~cm} /$ week $) \quad(\mathrm{p}=0.024)$. Similarly Mean increment in Length was significantly higher in SGA neonates $(0.932 \pm 0.18 \mathrm{~cm} /$ week $)$ as compare to AGA Neonates 
$(0.912 \pm 0.073 \mathrm{~cm} /$ week $)$ with equal duration of $\mathrm{KMC}(\mathrm{p}=0.032)$.

Mother or KMC care provider of the both groups have received same level counselling, by the same motivator, motivation and support throughout the study period were provided; but however, baseline characteristics of the Mother or KMC care provider was not studied in the detail. Throughout the study we have encouraged the mother or KMC provider to provide maximum duration of KMC to their neonates, during both day and night time, and we were able to achieve of at least 10.7hours/day mean hours of KMC in both the group. More increment in the growth parameter may be observed with practice of long or continuous practice of KMC. No significant difference was seen in length was seen between SGA than AGA preterm neonates.

Rao et $\mathrm{al}^{(12)}$ had conducted a randomized control trial to study efficacy of KMC in LBW neonates which shows significant improvement in growth parameters preterm neonates as compared to that in the term neonates. A study conducted by Vohra et al at ${ }^{(13)}$ our institute in 2014-2016 states that significant improvement of growth parameters in LBW SGA neonates as compared to that of LBW AGA neonates, however detailed comparison between preterm AGA and SGA was not studied. There was no study have been reported regarding the efficacy KMC in LBW preterm AGA and LBW preterm SGA neonates. There was no significant difference observed in the duration of KMC provided in both the study groups.

\section{Conclusion}

KMC is effective in increment of all three growth parameters (weight, length and head circumference) of low birth weight preterm neonates which is significantly more in preterm SGA neonates as compared to that in preterm AGA neonates. Thus, without using special equipment, the KMC strategy can offer improved care to preterm LBW babies. These findings support wider implementation of effective KMC in improving the outcome of SGA neonates as they are at risk of various complications. Also, comparatively longer duration of KMC is required in case of LBW preterm AGA infants.

Conflict of Interest: There was no conflict of interest related to this study.

\section{Acknowledgement}

We are sincerely thankful to the neonates, the mothers; and their families for co-operating with us and abiding by the guidelines of KMC provision as explained to them. We are also grateful to the nursing staff and the KMC instructor for their unmatchable support shown during the study; truly, the study would have been practically impossible without them.

\section{References}

1. https://data.unicef.org/topic/childsurvival/neonatal-mortality/

Shah J, Siyal AA, Taqi T. NEONATAL CARE UNIT. The Professional Medical Journal. 2018 Dec 8;25(12):1945-8.

2. Singh Mehrban. Disorders of weight and gestation. In: Singh Mehrban., editor. Care of the newborn. 4th edn. Sagar Publication; New Delhi: 1991. pp. 112125.

3. Charpak, N., Gabriel Ruiz, J., Zupan, J., Cattaneo, A., Figueroa, Z., Tessier, R., Cristo, M., Anderson, G., Ludington, S., Mendoza, S. and Mokhachane, M., 2005. Kangaroo mother care: 25 years after. Acta Paediatrica, 94(5), pp.514-522.

4. Charpak N, Figueroa Z (2001) Kangaroo mother care programme practical rules Bogota, Columbia: Kangaroo Foundation.

5. Athanasopoulou, E. and Fox, J.R., 2014. Effects of kangaroo mother care on maternal mood and interaction patterns between parents and their preterm, low birth weight infants: a systematic review. Infant mental health journal, 35 (3), pp.245-262. 
6. Joshi, Devesh \&Nainiwal, Lalit. (2020). Effect of kangaroo mother care in preterm versus term intra uterine growth restriction neonates. International Journal of Contemporary Pediatrics. 7. 807. 10.18203/2349-3291.ijcp20201135.

7. Subedi K, Aryal DR, Gurubacharya SM. Kangaroo mother care for low birth weight babies: a prospective observational study. J Nepal PaediatrSoci. 2009;29(1):6-9.

8. Swarnkar, Keerti\&Vagha, Jayanta. (2016). Effect of Kangaroo Mother Care on Growth and Morbidity Pattern in Low Birth Weight Infants. Journal of Krishna Institute of Medical Sciences University. 5. 91-99.

9. Rahman, Maksudur. (2017). Kangaroo Mother Care for Low Birth Weight Babies: A Randomized Controlled Trial in a Tertiary Care Hospital of Bangladesh. Journal of Pediatrics \& Neonatal Care. 7. 10.15406/jpnc.2017.07.00285.

10. Singh M (2000) Temperature regulation. In: Care of the new-born. Singh M. 5th edition. New Delhi: Sagar Publications 2000: 190-197.

11. Kangaroo Mother Care (2003) a practical guide. Department of Reproductive Health and Research Geneva: World Health Organisation 2003: 41-43.

12. Suman Rao PN, Udani R, Nanavati R. Kangaroo mother care for low birth weight infants: a randomized controlled trial. Ind Pediatr. 2008;45(1): 17.

13. Vohra, A.S., Shah, B.H. and Mehariya, K.M., 2017. Effect of kangaroo mother care on feeding, morbidity and neuro development of low birth weight neonates. Int J Contemp Med Res, 4, pp.1029-32. 